\title{
Associations of parental and perinatal factors with subsequent risk of stress-related disorders: a nationwide cohort study with sibling comparison
}

\author{
Yuchen Li iD ${ }^{1,2,3}$, Arvid Sjölander ${ }^{3}$, Huan Song (iD ${ }^{2,4}$, Sven Cnattingius ${ }^{5}$, Fang Fang ${ }^{6}$, Qian Yang ${ }^{3}$, Lorena Fernández de la Cruz (iD ${ }^{7,8}$, \\ David Mataix-Cols (iD ${ }^{7,8}$, Gustaf Brander (iD) ${ }^{7}$, Jiong Li (iD) ${ }^{9}$, Wei Zhang ${ }^{1,2}$, Katja Fall, ${ }^{6,10}$, Brian M. D'Onofrio ${ }^{3,11}$, Catarina Almqvist ${ }^{3,12}$, \\ Paul Lichtenstein (D) ${ }^{3}$, Unnur A. Valdimarsdóttir (D) ${ }^{3,4,13 \times}$ and Donghao Lu (D) ${ }^{2,6,13 凶}$
}

(c) The Author(s) 2021

Little is known about the contribution of pregnancy-related parental and perinatal factors to the development of stress-related disorders. We aimed to investigate whether parental/perinatal adversities entail higher risks of stress-related disorders in the offspring, later in life, by accounting for genetic and early environmental factors. Based on the nationwide Swedish registers, we conducted a population-based cohort study of 3,435,747 singleton births (of which 2,554,235 were full siblings), born 1973-2008 and survived through the age of 5 years. Using both population- and sibling designs, we employed Cox regression to assess the association between parental and perinatal factors with subsequent risk of stress-related disorders. We identified 55,511 individuals diagnosed with stress-related disorders in the population analysis and 37,433 in the sibling analysis. In the population-based analysis we observed increased risks of stress-related disorders among offspring of maternal/paternal age $<25$, single mothers, parity $\geq 4$, mothers with $\mathrm{BMI} \geq 25$ or maternal smoking in early pregnancy, gestational diabetes, and offspring born moderately preterm (GA 32-36 weeks), or small-for-gestational-age. These associations were significantly attenuated toward null in the sibling analysis. Cesarean-section was weakly associated with offspring stress-related disorders in population [hazard ratio (HR) $1.09,95 \%$ confidence interval (CI) 1.06-1.12] and sibling analyses (HR 1.10,95\% Cl 1.02-1.20). Our findings suggest that most of the observed associations between parental and perinatal factors and risk of stress-related disorders in the population analysis are driven by shared familial environment or genetics, and underscore the importance of family designs in epidemiological studies on the etiology of psychiatric disorders.

Molecular Psychiatry (2022) 27:1712-1719; https://doi.org/10.1038/s41380-021-01406-5

\section{INTRODUCTION}

Most people are exposed to some stressful life events or trauma throughout the life span [1]. Such events raise the risk of severe psychiatric reactions, including posttraumatic stress disorder (PTSD) and acute stress reaction (ASR), adjustment disorder, and other stress reactions [1, 2]. These stress-related disorders are associated with a number of adverse health consequences, including cardiovascular [3] and metabolic diseases [4], autoimmune diseases [5], dementia [6], suicide [7], and premature mortality [8]. Some risk factors have been identified, including female sex, socioeconomic disadvantage, history of chronic or major somatic illness, individual and family history of psychiatric disorders, and trauma severity, which have all been associated with stress-related disorders [9-11]. The prevalence of PTSD is relatively stable from adolescence through midlife [12]. However, except for childhood traumatic experiences [13], little is known about potential risk factors occurring before or shortly after birth [14].

Animal models have shown that parental factors during pregnancy and perinatal stressors may influence the development of early psychopathology [15]. Emerging evidence also supports that adverse parental and perinatal factors may be associated with a range of psychiatric disorders in humans [16-18]. For instance, individuals with low birth weight have been reported to be at higher risks for depression [16] and obsessive-compulsive disorder [17], whereas preterm birth is associated with increased risks of obsessive-compulsive disorder [17], tic disorders [18] and suicide attempt [19]. To date, it is unknown whether adverse parental or

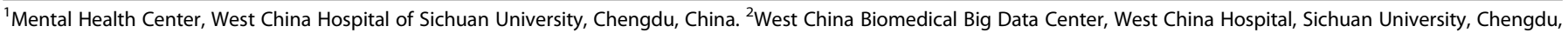

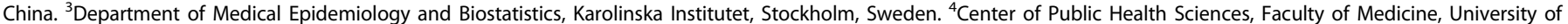

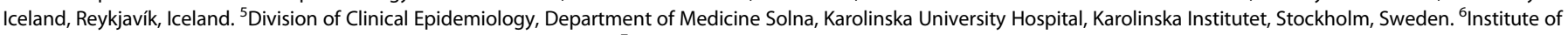

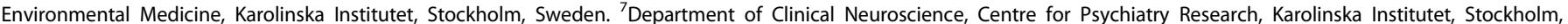

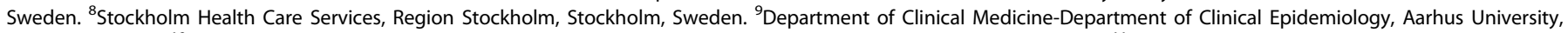

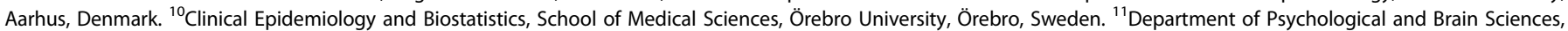

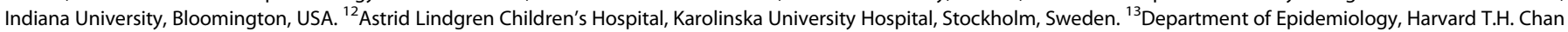
School of Public Health, Boston, MA, USA. ${ }^{\circledR}$ email: unnurav@hi.is; donghao.lu@ki.se
} 
perinatal factors are associated with subsequent risk of stressrelated disorders. Familial factors, e.g., genetics and socioeconomic status, may account for the association between parental and/or perinatal exposures and offspring's outcomes [20, 21], highlighting the need of family-based designs, e.g., using sibling comparison, in this field.

Leveraging a nationwide population birth cohort in Sweden, we aimed to identify parental and perinatal factors associated with risk of stress-related disorders later in life. To disentangle the familial influence on the studied associations, we also performed a sibling analysis [20].

\section{MATERIALS AND METHODS Study population}

Every Swedish resident is assigned a unique personal identity number (PIN) at birth or at immigration, which is used for data linkage across registers. Since 1973, the Swedish Medical Birth Register (MBR) has collected information on $>98 \%$ of deliveries in Sweden, starting from women's first visit to prenatal care, through delivery and birth care [22]. Information includes mothers' and infants' PINs, maternal characteristics, mode of delivery, pregnancy complications, and birth outcomes. Based on this register, we identified 3,546,149 singleton live births from January 1st, 1973 to December 31st, 2008. We excluded stillbirths ( $n=$ $13,365)$ and individuals without information on PIN $(n=5041)$, gestational age $(n=8323)$ or sex $(n=1)$. Because stress-related disorders are usually not diagnosed in individuals below 5 years of age [23], we followed all individuals from their 5th birthday. Therefore, we also excluded 83,672 individuals who either died or emigrated before age 5 , leaving 3,435,747 individuals for the population analysis. By linking to the Migration [24] and Cause of Death Registers [25], the follow-up was censored at first emigration, death or December 31st, 2013, whichever came first.

To identify full siblings, we obtained information on biological fathers through linkage to the Multi-Generation Register (MGR), while maternal PINs are already documented in the MBR. The MGR documents parental information on Swedish residents that were born from 1932 onward and were alive since 1961 [26]. In total, we identified 2,554,235 (74.3\%) individuals having at least one full sibling (i.e., sharing the same biological mother and father) for the sibling analyses.

\section{Ascertainment of parental and perinatal factors}

We defined factors originating from early pregnancy which are related to the parents as parental factors and factors pertaining to the time around birth as perinatal factors. We obtained information on parental and perinatal factors from the MBR, while the National Patient Register was used to complement diagnostic information on maternal hypertensive, diabetic, and psychiatric disorders (see Supplementary Table 1 for diagnostic codes).

Parental factors. Information on maternal age at childbirth and maternal relationship status (i.e., living together or not) with the offspring's father was extracted from the MBR, while paternal age at childbirth was calculated from the MGR. Information on parity (including the present birth) was extracted from the MBR and categorized as $1,2,3, \geqslant 4$ (the birth of fourth child or thereafter). Maternal weight and height at early pregnancy were recorded at the first parental visit (usually at 12 gestational weeks) [27] from 1992 onward. Maternal body mass index (BMI) was calculated and classified as $<18.5,18.5$ to $<25$ (reference), 25 to $<30$, and $\geqslant 30 \mathrm{~kg} / \mathrm{m}^{2}$. Maternal smoking was documented at the first parental visit from 1982 onward, and grouped as no smoking, 1-9, and $\geq 10$ cigarettes per day [28]. We also studied common pregnancy complications, such as maternal hypertensive (i.e., preeclampsia and essential hypertension) and diabetic diseases (i.e., gestational diabetes and pregestational diabetes; information is available from 1987 onward). Analyses of maternal BMl, smoking, and diabetes were restricted to individuals born after 1992, 1982, and 1987, respectively.

Perinatal factors. Mode of delivery was categorized as cesarean section, instrumental vaginal delivery (forceps or vacuum extraction), and noninstrumental vaginal delivery. Gestational age was primarily estimated from the results of ultrasonography performed early in the second trimester, which was introduced in Sweden in the late 1970s and was offered to all pregnant women since 1990 [29]. Gestational age was categorized as very preterm (gestational age $<32$ completed weeks), moderately preterm (32-36 weeks), term (37-41 weeks), and post-term birth ( $\geq 42$ weeks). We used the ultrasound-based, sex-specific Swedish reference curve for fetal growth [30] to derive birth weight for gestational age percentiles and categorized it as $<3 \mathrm{rd}$, 3rd to $<10$ th, 10th to 90th, $>90$ th to 97 th, and $>97$ th percentile. The Apgar score is a quick assessment for the newborn's vital status, by evaluating heart rate, respiratory effort, reflex irritability, muscle tone, and color after delivery [31]. Low $5 \mathrm{~min}$ Apgar score was defined as $<7$ at $5 \mathrm{~min}$.

\section{Ascertainment of stress-related disorders}

We defined stress-related disorders as PTSD, ASR, adjustment disorder, and other stress reactions. Through linkage to the National Patient Register, we identified any first inpatient hospital or outpatient specialist visit with a stress-related disorder as the main diagnosis, using the codes of the 8-10th Swedish versions of International Classification of Disease (ICD-8: 307, 308.4; ICD-9: 308, 309; and ICD-10: F43; listed in Supplementary Table 1). The National Patient Register covers $86 \%$ psychiatric diagnoses of the entire country from 1973, and became nationwide from 1987 [32]. From 2001, the Register also collected the hospital-based outpatient visits (initial coverage $>80 \%$ ) [32].

\section{Covariates}

Information on covariates was primarily extracted from the MBR and the MGR, including maternal country of birth (Nordic or non-Nordic countries; the former includes Denmark, Finland, Iceland, Norway, and Sweden), offspring year of birth, and sex. We assessed history of parental (both maternal and paternal) psychiatric disorders by using any diagnosis of a psychiatric disorder, identified from the National Patient Register, before the pregnancy. As a proxy for socioeconomic status, we obtained the highest educational level of the mother from the Education Register.

\section{Statistical analysis}

First, we estimated the crude incidence rates (IRs) of stress-related disorders by baseline characteristics. In the primary analysis, we calculated crude IRs and hazard ratios (HRs) with 95\% confidence intervals (Cls) of stress-related disorders for each parental and perinatal factor in the population analysis. We used Cox regression with attained age as the underlying timescale, stratified by year of birth in groups and adjusted for offspring sex, maternal relationship status, maternal country of birth, maternal highest educational level, and history of parental psychiatric disorders. To address confounding by familial factors, we employed Cox regression stratified by sibling sets and adjusted for offspring sex, year of birth (in groups), and maternal relationship status. We described numbers of families and siblings discordant on studied parental/perinatal factors and stress-related disorders in Supplementary Table 2. We did not perform sibling analyses for maternal chronic diseases (i.e., pregestational diabetes and essential hypertension), because all siblings (i.e., no exposure variation between these siblings). We tested the proportional hazard assumption using the Schoenfeld residual test and found no violation for any of the covariates [33].

To better control for the maternal background factors in the population analysis, we applied a finer adjustment for maternal country of birth (Sweden, other Nordic, European, African, Asian, or other countries) in an additional analysis. To increase the comparability between results from the population and sibling cohorts, we applied the population analysis by restricting to individuals with at least one sibling. To shed light on independent effects, we also performed an analysis by mutually adjusting for parental or perinatal factors, respectively.

Individuals with stress-related disorders often have other comorbid psychiatric disorders (e.g., depression, anxiety, substance abuse) [34], which may drive the observed associations. We therefore identified psychiatric comorbidities for all individuals as any inpatient or outpatient visit with a main diagnosis of a psychiatric disorder other than stressrelated disorders during the follow-up from the National Patient Register (see diagnostic codes in Supplementary Table 1). To test whether the increased risk of stress-related disorders was driven by psychiatric comorbidities, we conducted a sensitivity analysis by restricting the cohort to individuals with stress-related disorders without psychiatric comorbidities, either before or after the diagnosis of stress-related disorder. To shed light on the subtype of more severe stress-related disorders, we performed separate analyses for PTSD and ASR. 
Table 1. Baseline characteristics of individuals included in the population and sibling analyses.

\begin{tabular}{|c|c|c|c|c|c|c|}
\hline & \multicolumn{3}{|c|}{ Population analysis } & \multicolumn{3}{|l|}{ Sibling analysis } \\
\hline & Individuals, $N$ & Cases, $\mathbf{N}$ & IR & Individuals, $N$ & Cases, $\mathbf{N}$ & IR \\
\hline Total number & $3,435,747$ & 55,511 & 0.9 & $2,554,235$ & 37,433 & 0.8 \\
\hline \multicolumn{7}{|l|}{ Year of birth } \\
\hline 1973-1977 & 488,419 & 13,753 & 0.9 & 267,878 & 6965 & 0.8 \\
\hline 1978-1981 & 358,665 & 9998 & 1.0 & 274,943 & 6924 & 0.9 \\
\hline 1982-1986 & 449,711 & 12,127 & 1.1 & 369,997 & 9074 & 1.0 \\
\hline 1997-2001 & 412,063 & 1603 & 0.4 & 331,068 & 1086 & 0.3 \\
\hline $2002-2008$ & 666,957 & 344 & 0.2 & 436,559 & 205 & 0.1 \\
\hline \multicolumn{7}{|l|}{ Offspring sex } \\
\hline Female & $1,669,979$ & 35,506 & 1.2 & $1,240,080$ & 24,076 & 1.1 \\
\hline Male & $1,765,768$ & 20,005 & 0.6 & $1,314,155$ & 13,357 & 0.6 \\
\hline \multicolumn{7}{|c|}{ Maternal education, years } \\
\hline$<10$ & 432,679 & 11,262 & 1.2 & 280,929 & 6762 & 1.2 \\
\hline $10-12$ & $1,632,372$ & 28,769 & 1.0 & $1,209,511$ & 19,387 & 0.9 \\
\hline$\geqslant 13$ & $1,347,481$ & 15,019 & 0.7 & $1,054,163$ & 11,077 & 0.7 \\
\hline Unknown & 23,215 & 461 & 1.4 & 9632 & 207 & 1.5 \\
\hline
\end{tabular}

$N$ number, IR incidence rate (per 1000 person-years in crude).

The data were prepared in SAS statistical software, version 9.4 (SAS Institute, Cary, NC) and analyzed in Stata 15.1 (STATA, College Station, TX). The study was approved by the Regional Ethics Review Board in Stockholm, Sweden (reference number 2013/862-31/5). All data were pseudonymized prior to analyses. Written consent was not required given the nature of population registry resources.

\section{RESULTS}

\section{Baseline characteristics}

During the long-term follow-up up to 35 years (median 17.4 years), we identified 55,511 individuals diagnosed with stress-related disorders for the population analysis and 37,433 for the sibling analysis. The mean age at diagnosis was 24.2 years (standard deviation, 6.9 years). The crude IR of stress-related disorders was higher among individuals born before 1997, in females, in offspring of mothers with lower educational attainment, not living with a partner, and when parents had a history of psychiatric disorders before pregnancy (Table 1).

\section{Parental factors}

In the population analysis, we observed increased risks of stress-related disorders among offspring of younger mothers and fathers ( $\leq 24$ years), older mothers ( $\geqslant 35$ years), not cohabiting mothers, parity $\geqslant 4$, history of parental psychiatric disorders before pregnancy, mothers with $B M I \geqslant 25 \mathrm{~kg} / \mathrm{m}^{2}$ in early pregnancy, smoking in early pregnancy, and mothers with essential hypertension or gestational diabetes. However, all these associations were attenuated toward null in the sibling analyses (Table 2). For instance, maternal smoking associated HRs $(95 \% \mathrm{Cls})$ were in population analyses 1.45 (1.41-1.50) for 1-9 cigarettes per day and $1.66(1.61-1.72)$ for $\geqslant 10$ cigarettes per day, while corresponding HRs $(95 \% \mathrm{Cls})$ in sibling analyses attenuated to $1.06(0.97-1.16)$ and 1.04 (0.93-1.16), respectively.

\section{Perinatal factors}

In the population analysis, we observed elevated risks of stressrelated disorders among offspring born at 32-36 gestational weeks and birth weight for gestational age <10th percentile or $>97$ th percentile. However, these associations were not observed in the sibling analyses. In population analysis, we found increased risk of stress-related disorders in individuals born at $<32$ gestational weeks (HR 1.35, 95\% Cl 1.22-1.49) and with a 5-minute Apgar score <7 (HR 1.22, 95\% Cl 1.12-1.32) (Table 3). In the sibling analysis, these HRs were attenuated to $1.16(95 \% \mathrm{Cl}$ $0.93-1.45)$ and $1.13(95 \% \mathrm{Cl} 0.95-1.33)$, respectively. Cesarean section was weakly associated with increased risk of stress-related disorders in both population ( $\mathrm{HR} 1.09,95 \% \mathrm{Cl} 1.06-1.12)$ and sibling (HR 1.10, 95\% Cl 1.02-1.20) analyses.

\section{Additional analyses}

In the population analysis restricted to individuals with at least one sibling, the associations between parental and perinatal factors and risks of stress-related disorders were largely comparable to the associations noted in the full population cohort. However, a stronger association was noted between higher parity (i.e., the birth of fourth or higher order children) and stress-related disorders among individuals with siblings (Supplementary Table 3). We also obtained largely similar results for parental factors by mutually adjusting for parental factors in both population and sibling analyses (Supplementary Table 4), for perinatal factors after mutual adjustments (Supplementary Table 5) and after a finer adjustment for maternal country of birth (Supplementary Table 6). Largely comparable, yet weaker associations in population and sibling analyses were observed by restricting to stress-related disorders without psychiatric comorbidity, except for the increased risk among offspring of young fathers (paternal age at childbirth before 24 years) in the sibling analysis (Supplementary Tables 7,8$)$. Of note, the association between cesarean section 
Table 2. Associations of parental factors with subsequent risk of stress-related disorders.

\begin{tabular}{|c|c|c|c|c|c|c|}
\hline & \multicolumn{3}{|c|}{ Population analysis $^{a}$} & \multicolumn{3}{|c|}{ Sibling analysis ${ }^{\mathbf{b}}$} \\
\hline & Individuals, $\mathbf{N}$ & Cases, $\boldsymbol{N}$ (IR) & HR $(95 \% \mathrm{Cl})$ & Individuals, $N$ & Cases, $N$ (IR) & HR (95\% Cl) \\
\hline \multicolumn{7}{|c|}{ Maternal age at childbirth, years } \\
\hline $20-24$ & 730,053 & $16,301(1.1)$ & $1.24(1.21-1.27)$ & 550,006 & $11,439(1.0)$ & $0.99(0.93-1.05)$ \\
\hline $25-29$ & $1,223,891$ & $18,508(0.8)$ & 1.00 & 955,914 & $13,415(0.8)$ & 1.00 \\
\hline $30-34$ & 933,024 & $11,216(0.8)$ & $0.97(0.95-0.99)$ & 700,410 & $7472(0.7)$ & $1.02(0.95-1.09)$ \\
\hline \multicolumn{7}{|c|}{ Paternal age at childbirth, years } \\
\hline$<20$ & 25,560 & $982(1.9)$ & $1.90(1.78-2.03)$ & 12,051 & $452(1.7)$ & $1.18(0.98-1.41)$ \\
\hline $20-24$ & 379,304 & $9881(1.2)$ & $1.31(1.28-1.35)$ & 268,507 & $6418(1.1)$ & $1.05(0.98-1.11)$ \\
\hline $25-29$ & $1,044,087$ & $18,022(0.9)$ & 1.00 & 813,199 & $13,024(0.8)$ & 1.00 \\
\hline $30-34$ & $1,081,295$ & $14,459(0.8)$ & $0.92(0.90-0.95)$ & 835,673 & $10,270(0.7)$ & $0.99(0.94-1.05)$ \\
\hline Cohabitation & $2,769,214$ & $38,388(0.9)$ & 1.00 & $2,133,886$ & $27,883(0.8)$ & 1.00 \\
\hline \multicolumn{7}{|l|}{ Parity } \\
\hline 1 & $1,459,407$ & $23,310(0.9)$ & 1.00 & 958,719 & $14,326(0.8)$ & 1.00 \\
\hline 2 & $1,264,262$ & $18,992(0.9)$ & $0.91(0.90-0.93)$ & $1,042,972$ & $13,961(0.8)$ & $0.93(0.89-0.97)$ \\
\hline 3 & 508,833 & $8763(1.0)$ & $0.99(0.97-1.01)$ & 394,508 & $6023(0.9)$ & $0.88(0.81-0.95)$ \\
\hline$\geqslant 4$ & 203,245 & $4446(1.3)$ & $1.21(1.18-1.26)$ & 158,036 & $3123(1.2)$ & $0.80(0.71-0.91)$ \\
\hline \multicolumn{7}{|c|}{ Maternal BMI at early pregnancy, $\mathrm{kg} / \mathrm{m}^{2 \mathrm{C}}$} \\
\hline$<18.5$ & 32,223 & $173(0.6)$ & $1.04(0.91-1.20)$ & 22,588 & $132(0.6)$ & $0.74(0.43-1.28)$ \\
\hline 18.5 to $<25$ & 804,551 & $3180(0.5)$ & 1.00 & 596,592 & $2228(0.4)$ & 1.00 \\
\hline 25 to $<30$ & 307,358 & $1296(0.6)$ & $1.14(1.07-1.20)$ & 227,532 & $923(0.5)$ & $1.01(0.80-1.27)$ \\
\hline Preeclampsia & 92,693 & $1377(0.9)$ & $1.02(0.96-1.07)$ & 63,036 & $848(0.8)$ & $1.06(0.94-1.19)$ \\
\hline Essential hypertension & 20,713 & $247(1.0)$ & $1.15(1.02-1.31)$ & - & - & - \\
\hline \multicolumn{7}{|l|}{ Maternal diabetes ${ }^{\mathrm{e}}$} \\
\hline No & $2,086,953$ & $19,299(0.8)$ & 1.00 & $1,603,650$ & $14,241(0.7)$ & 1.00 \\
\hline Gestational diabetes & 18,853 & $184(0.9)$ & $1.15(0.99-1.32)$ & 13,615 & $127(0.9)$ & $0.66(0.46-0.96)$ \\
\hline Pregestational diabetes & 13,513 & $150(1.0)$ & $1.18(1.01-1.39)$ & - & - & - \\
\hline
\end{tabular}

Note: Individuals with missing information on paternal age at childbirth $(N=23,720,0.69 \%)$, maternal cohabitation status $(N=261,739,7.62 \%)$, maternal BMI at early pregnancy $(N=208,539,14.12 \%)$, smoking during early pregnancy $(N=190,886,7.37 \%)$ were not included in the corresponding analysis. Individuals with essential hypertension or pregestational diabetes were not included in the sibling analysis.

HRs and $95 \% \mathrm{Cls}$ were estimated from multivariable Cox regression models.

$N$ number, IR incidence rate (per 1000 person-years in crude), $H R$ hazard ratio, $C l$ confidence interval.

aHRs were stratified on calendar year of birth (1973-1977, 1978-1981, 1982-1986, 1987-1991, 1992-1996, 1997-2001, or 2002-2008), and adjusted for offspring sex (female or male), attained age, maternal country of birth (Nordic, non-Nordic, or unknown), maternal educational level $(<10$ years,10-11, 12, $13-14,15+$, or unknown), and history of parental psychiatric disorders.

${ }^{b}$ HRs were stratified on full-siblingship and adjusted for offspring sex (female or male), attained age, and calendar year of birth.

'This analysis was restricted to individuals born during 1992-2008 because information on maternal BMI at early pregnancy was largely complete from 1992 onward.

${ }^{\mathrm{d}}$ This analysis was restricted to individuals born during 1982-2008 because information on maternal smoking during pregnancy was available from 1982 onward.

${ }^{\mathrm{e}}$ This analysis was restricted to individuals born during 1987-2008 because information on maternal diabetes was available from 1987 onward. 
Table 3. Associations of perinatal factors with subsequent risk of stress-related disorders.

\begin{tabular}{|c|c|c|c|c|c|c|}
\hline & \multicolumn{3}{|c|}{ Population analysis $^{a}$} & \multicolumn{3}{|l|}{ Sibling analysis ${ }^{\mathbf{b}}$} \\
\hline & Individuals, $N$ & Cases, $\mathbf{N}$ (IR) & HR $(95 \% \mathrm{Cl})$ & Individuals, $\mathbf{N}$ & Cases, $\mathbf{N}$ (IR) & HR $(95 \% \mathrm{Cl})$ \\
\hline \multicolumn{7}{|l|}{ Mode of delivery } \\
\hline Assisted vaginal delivery & 223,453 & $3001(0.8)$ & $0.97(0.94-1.01)$ & 150,139 & $1880(0.7)$ & $1.03(0.95-1.11)$ \\
\hline Cesarean section & 405,030 & $6107(1.0)$ & $1.09(1.06-1.12)$ & 274,531 & $3853(0.9)$ & $1.10(1.02-1.20)$ \\
\hline \multicolumn{7}{|l|}{ Gestational age, weeks } \\
\hline $32-36$ & 150,297 & $2816(1.1)$ & $1.15(1.10-1.19)$ & 103,199 & $1771(1.0)$ & $0.99(0.91-1.07)$ \\
\hline $37-41$ & $2,937,327$ & $46,088(0.9)$ & 1.00 & $2,204,446$ & $29,557(0.8)$ & 1.00 \\
\hline$\geqslant 42$ & 329,573 & $6222(0.9)$ & $1.02(1.00-1.05)$ & 235,276 & $4034(0.9)$ & $1.00(0.95-1.06)$ \\
\hline \multicolumn{7}{|c|}{ Birth weight for gestational age, percentile } \\
\hline$<3 r d$ & 104,580 & $2565(1.2)$ & $1.23(1.18-1.28)$ & 67,113 & $1469(1.1)$ & $1.00(0.91-1.10)$ \\
\hline$>97$ th & 112,165 & $1730(0.9)$ & $1.06(1.01-1.11)$ & 87,691 & $1224(0.9)$ & $1.06(0.97-1.17)$ \\
\hline \multicolumn{7}{|l|}{ Apgar score at $5 \min ^{c}$} \\
\hline Low & 31,572 & $608(1.1)$ & $1.22(1.12-1.32)$ & 21,139 & $363(1.0)$ & $1.13(0.95-1.33)$ \\
\hline Normal & $3,182,721$ & $49,080(0.9)$ & 1.00 & $2,392,981$ & $33,762(0.8)$ & 1.00 \\
\hline
\end{tabular}

Note: Individuals with missing information on birth weight for gestational age $(N=12,960,0.38 \%)$ and missing information on 5 min $A p g a r ~ s c o r e ~(N=221,454$, $6.45 \%)$ were not included in the corresponding analysis.

HRs and $95 \% \mathrm{Cls}$ were estimated from multivariable Cox regression models.

$N$ number, IR incidence rate (per 1000 person-years in crude), HR hazard ratio, $\mathrm{Cl}$ confidence interval.

a HRs were stratified on calendar year of birth (1973-1977, 1978-1981, 1982-1986, 1987-1991, 1992-1996, 1997-2001, or 2002-2008), and adjusted for offspring sex (female or male), attained age, maternal country of birth (Nordic, non-Nordic, or unknown), maternal educational level ( $<10$ years,10-11, 12, 13-14, 15+, or unknown), and history of parental psychiatric disorders.

${ }^{\mathrm{b}} \mathrm{HRs}$ were stratified on full-siblingship and adjusted for offspring sex (female or male), attained age, and calendar year of birth.

'Low Apgar score was defined as Apgar score $<7$.

delivery and stress-related disorders remained in the population analysis, but was further attenuated in the sibling analysis. In the analysis of subtypes of stress-related disorders, similar associations were observed between PTSD and ASR, except for moderately large differences in the associations between gestational age and stress-related disorders; the elevated risk among individuals born preterm in the population analysis remained in the sibling analysis for PTSD but not for ASR (Supplementary Table 9).

\section{DISCUSSION}

Using a nationwide birth cohort in Sweden with complete followup up to 35 years, our results do not support a causal role of many parental and perinatal factors in the development of stress-related disorders. The observed increased risks of stress-related disorders by adverse parental factors in the population analysis were largely attenuated to null in the sibling analysis, suggesting strong confounding by familial (environmental and genetic) factors shared by siblings. The associations of very preterm birth and low $5 \mathrm{~min}$ Apgar score with stress-related disorders were also attenuated by $40-60 \%$ in the sibling analysis, indicating that the association observed in the population analysis is largely driven by shared familial factors. The weak association we observed between cesarean section and risk of stress-related disorders in both population and sibling analyses was further attenuated in the sibling analysis when restricting to individuals without psychiatric comorbidities.

A growing body of evidence indicates that adverse fetal development (i.e., maternal diseases during pregnancy, low birth weight and preterm birth) may predispose individuals to mood and anxiety disorders [35], which are highly comorbid with stressrelated disorders [36, 37]. However, none of these studies employed a sibling analysis to unmeasured confounding by familial environment and genetics [20]. The sibling analysis represents an advanced study design to account for confounders that are shared within families and fixed over time [38, 39]. In contrast, the population analysis inevitably incorporates a number of unmeasured confounders that are inherently controlled for when comparing siblings. For example, accumulating evidence suggests that familial factors, particularly genetic factors, drive the associations between maternal smoking during pregnancy and offspring cognitive and behavioral problems [20]. It is likely that familial factors also account for the increased risk of stress-related disorders in the population analysis since the association is attenuated to null in the sibling comparison. The sibling design thus has strong implications for causal inferences which is the purpose of the present study.

Our findings suggest that the increased risk of stress-related disorders among individuals exposed to parental adversity in the population setting is potentially explained by familial characteristics that are clustered within the family rather than putative biological effects. Other parental factors such as maternal smoking, overweight during pregnancy are highly correlated with familial environment. For instance, smoking and obesity are common in socially deprived households who are also at risk for PTSD [40-42]. Our data illustrate that the elevated risk of stressrelated disorders among individuals with maternal smoking or overweight during pregnancy in the population analysis was attenuated to null when comparing within siblings, who share the familial environment in early life. 
However, several perinatal adversities, e.g., preterm birth and small for gestational age, may to a large extent be attributable to genetic factors [43, 44]. Indeed, emerging evidence supports the contribution of the individual's genetic makeup to stress-related disorders [45]. Twin studies have indicated that the heritability of PTSD ranges from 23.5 to $71 \%[46,47]$, while recent genome-wide association studies have successfully identified robust genetic markers associated with PTSD and stress-related disorders [9, 48]. We found that the increased risk of stress-related disorders associated with a few perinatal factors in the population analysis were attenuated by $40-60 \%$ when comparing with full siblings, suggesting a genetic overlap between these factors and stressrelated disorders. Preterm birth has been be associated with a range of psychiatric disorders, including bipolar affective disorder, autism spectrum disorders, substance use disorders, and attention-deficit/hyperactivity disorder [19]. The heritability of preterm birth is estimated up to $40 \%$ in a twin study [49] and $20 \%$ in a genome-wide association study [50]. It is not implausible that the observed association between preterm birth and stress-related disorders is explained by genetic factors that may influence both outcomes. It has been reported that low $5 \mathrm{~min}$ Apgar score is associated with less stress resilience in young adulthood [51]. Although the Apgar score can be seen as a proxy to many parental and perinatal conditions, the heritability is estimated to be $42 \%$ [52]. Further research is needed to confirm the shared genetic contribution between $5 \mathrm{~min}$ Apgar scores and stress-related disorders.

Previous studies have indicated that cesarean section is associated with increased risks of attention deficit and hyperactivity disorder, tic disorders, and obsessive-compulsive disorder in both population and sibling analyses $[17,18]$. Our data showed that individuals born by cesarean section are at mildly increased risk for stress-related disorders later in life. Although cesarean section is a result of many parental and intrapartum complications, this weak association remained after mutual adjustment for perinatal factors. However, the association was further attenuated by restricting to individuals without psychiatric comorbidities in the sibling analysis, suggesting that it may partly be driven by differences in the indication for cesarean section.

In line with previous studies [12], we observed higher IRs of stress-related disorder prevalence among female offsprings, offspring of mothers with lower educational attainment, and those not living with a partner, which are highly correlated with socioeconomic status $[53,54]$. We also noted a lower IR of stressrelated disorders among individuals born after 1997 which may be due to the fact that they had not reached the high-risk ages (median age at onset $=30$ years, 25 th percentile $=17$ years) during the follow-up through 2013 [55]. The elevated IRs among offspring of parents with a history of psychiatric disorders before pregnancy may be driven by both genetic factors and familial environment [55].

To the best of our knowledge, this is the first study to comprehensively investigate parental and perinatal risk factors for stress-related disorders later in life. A major strength of our study was the large-scale nationwide birth cohort with long-term followup, and a sibling-based design. With prospectively and independently collected data on both exposures and outcome, our analysis was minimally affected by selection or information biases. The sibling analysis showed that most associations observed in the population analysis are strongly biased by unmeasured familial confounding, highlighting the importance of using sibling designs when studying associations of this kind in epidemiological research [56].

Our study also has limitations. First, we only included stressrelated disorders diagnosed in hospital in-patient and outpatient care. Moreover, we lacked information on outpatient diagnoses before 2001. Although fairly good quality has been indicated for these usually specialist care-based diagnoses of stress-related disorders in the Swedish registers (the validity of PTSD diagnoses is $>80 \%$ ) [57], the present study does not capture stress-related disorders only diagnosed in primary care. However, individuals were always compared with their peers as we have stratified on birth year groups and used attained age at the underlying timescale in all analyses. Such underestimate of stress-related disorders is likely non-differential in relation to parental/perinatal factors and would have led to conservative results, partially responsible for the weaker estimates in sibling comparison. Second, because of the relatively young age of the individuals by the end of the follow-up, we only captured stressrelated disorders up to age of 40 years. However, we covered the age band of high prevalence of stress-related disorders [12] and likely subtypes most relevant to early-life factors. Third, individuals with siblings might be somewhat different from individuals without siblings. However, we observed largely similar associations in the overall population analyses and when limiting the population analysis to those with at least one sibling. Furthermore, the population and sibling analysis does not account for confounding factors that are time-varying within-families [58] (e.g., non-shared environmental factors, birth order effect) [59], and may result in bias if there are carry-over effects among siblings (i.e., effects of the exposure and/or the outcome of one sibling on the exposure and/or outcome of subsequent siblings) [56]. Fourth, exposures that are likely constant across pregnancies cannot be addressed by the sibling analyses. For instance, we did not perform sibling analyses for pregestational diabetes and essential hypertension, because of very limited exposure variation between siblings. Moreover, mothers smoking during the first pregnancy are more likely to smoke during following pregnancies [60]. Although we included a simple classification on cigarette consumption (1-9 vs. $\geq 10$ cigarettes per day), the full variation of maternal smoking across pregnancies might not be captured. Because time-varying parental/perinatal exposures do not occur at random and may be driven by other factors, we cannot rule out residual confounding. In addition, individuals exposed to parental or perinatal adversities are at risk for traumatic events in childhood or adolescence [61], leading to increased risk of stress-related disorder [62]. The mediating role traumatic events should be explored in future studies. Last, we only included a number of parental and perinatal factors that are common and well-documented in the Swedish MBR; less common exposures may also be of importance for the development of stress-related disorders and should be addressed in future studies.

In summary, our findings do not support an important role of many common parental or perinatal factors in the development of stress-related disorders later in life after careful consideration of familial confounders. Our study highlights the importance of taking familial confounders into account in observational studies of complex traits, such as stress-related disorders. Although these parental and perinatal factors are unlikely causally linked to stress-related disorders, the associations observed in the population analysis may guide strategies to identify high-risk groups.

\section{REFERENCES}

1. Kessler RC, Aguilar-Gaxiola S, Alonso J, Benjet C, Bromet EJ, Cardoso G, et al. Trauma and PTSD in the WHO World Mental Health Surveys. Eur J Psychotraumatol. 2017;8:1353383.

2. Carta M, Balestrieri M, Murru A, Hardoy M. Adjustment Disorder: epidemiology, diagnosis and treatment. Clin Pr Epidemiol Ment Heal. 2009;5:15.

3. Song H, Fang F, Arnberg FK, Mataix-Cols D, Fernández de la Cruz L, Almqvist C, et al. Stress related disorders and risk of cardiovascular disease: population based, sibling controlled cohort study. BMJ 2019;365:11255.

4. Dedert EA, Calhoun PS, Watkins LL, Sherwood A, Beckham JC. Posttraumatic Stress Disorder, Cardiovascular, and Metabolic Disease: A Review of the Evidence. Ann Behav Med. 2010;39:61-78. 
5. Song H, Fang F, Tomasson G, Arnberg FK, Mataix-Cols D, De La Cruz LF, et al. Association of stress-related disorders with subsequent autoimmune disease. JAMA - J Am Med Assoc. 2018;319:2388-2400.

6. Gradus JL, Horváth-Puhó E, Lash TL, Ehrenstein V, Tamang S, Adler NE, et al. Stress Disorders and Dementia in the Danish Population. Am J Epidemiol. 2019;188:493-9.

7. Gradus JL, Qin P, Lincoln AK, Miller M, Lawler E, Sorensen HT, et al. Posttraumatic Stress Disorder and Completed Suicide. Am J Epidemiol. 2010;171:721-7.

8. Kopp MS, Réthelyi J. Where psychology meets physiology: chronic stress and premature mortality-the Central-Eastern European health paradox. Brain Res Bull. 2004;62:351-67.

9. Tang B, Deng Q, Glik D, Dong J, Zhang L. A Meta-Analysis of Risk Factors for PostTraumatic Stress Disorder (PTSD) in Adults and Children after Earthquakes. Int J Environ Res Public Health. 2017;14:1-20.

10. Stukas AA, Dew MA, Switzer GE, DiMartini A, Kormos RL, Griffith BP. PTSD in heart transplant recipients and their primary family caregivers. Psychosomatics 1999:40:212-21.

11. Tortella-Feliu M, Fullana MA, Pérez-Vigil A, Torres X, Chamorro J, Littarelli SA, et al. Risk factors for posttraumatic stress disorder: An umbrella review of systematic reviews and meta-analyses. Neurosci Biobehav Rev. 2019;107:154-65.

12. Ditlevsen DN, Elklit A. The combined effect of gender and age on post traumatic stress disorder: Do men and women show differences in the lifespan distribution of the disorder? Ann Gen Psychiatry. 2010;9:32.

13. Brunault $P$, Lebigre $K$, Idbrik F, Maugé $D$, Adam $P$, Barrault $S$, et al. Childhood Trauma Predicts Less Remission from PTSD among Patients with Co-Occurring Alcohol Use Disorder and PTSD. J Clin Med. 2020; 9, undefined. https://doi.org/ 10.3390/jcm9072054.

14. Betts KS, Williams GM, Najman JM, Alati R. The association between birth weight and anxiety disorders in young adults. J Anxiety Disord. 2011;25:1060-7. https:// doi.org/10.1016/j.janxdis.2011.07.002.

15. Lautarescu A, Craig MC, Glover V. Prenatal stress: effects on fetal and child brain development. Int Rev Neurobiol. 2020;150:17-40.

16. Gale CR, Martyn CN. Birth weight and later risk of depression in a national birth cohort. Br J Psychiatry. 2004;184:28-33.

17. Brander $G$, Rydell $M$, Kuja-Halkola $R$, Fernández de la Cruz LF, Lichtenstein $P$, Serlachius $E$, et al. Association of perinatal risk factors with obsessive-compulsive disorder a population-based birth cohort, sibling control study. JAMA Psychiatry. 2016;73:1135-44.

18. Brander G, Rydell M, Kuja-Halkola R, Fernández de la Cruz L, Lichtenstein P, Serlachius $E$, et al. Perinatal risk factors in Tourette's and chronic tic disorders: a total population sibling comparison study. Mol Psychiatry. 2018;23:1189-97.

19. D'Onofrio $B M$, Class $Q A$, Rickert ME, Larsson $H$, Långström $N$, Lichtenstein $P$. Preterm birth and mortality and morbidity: a population-based quasi-experimental study. JAMA Psychiatry. 2013;70:1231-40.

20. D'Onofrio BM, Class QA, Rickert ME, Sujan AC, Larsson $H$, Kuja-Halkola $R$, et al. Translational Epidemiologic Approaches to Understanding the Consequences of Early-Life Exposures. Behav Genet. 2016;46:315-28.

21. D'Onofrio BM, Class QA, Lahey BB, Larsson H. Testing the Developmental Origins of Health and Disease Hypothesis for Psychopathology Using Family-Based Quasi-Experimental Designs. Child Dev Perspect. 2014;8:151.

22. Ludvigsson JF, Andersson E, Ekbom A, Feychting M, Kim JL, Reuterwall C, et al. External review and validation of the Swedish national inpatient register. BMC Public Health. 2011;11:450.

23. Gene-Cos N. Post-traumatic stress disorder: the management of PTSD in adults and children in primary and secondary care. Psychiatr Bull. 2006;30:357-357.

24. Ludvigsson JF, Almqvist $C$, Bonamy A-KE, Ljung R, Michaëlsson $K$, Neovius $M$, et al. Registers of the Swedish total population and their use in medical research. Eur J Epidemiol. 2016;31:125-36.

25. Brooke HL, Talbäck M, Hörnblad J, Johansson LA, Ludvigsson JF, Druid H, et al. The Swedish cause of death register. Eur J Epidemiol. 2017;32:765-73.

26. Ekbom A. The Swedish Multi-generation Register. Methods Mol Biol. 2011;675:215.

27. Dejin-Karlsson E, Hanson BS, Ostergren PO, Ranstam J, Isacsson SO, Sjöberg NO. Psychosocial resources and persistent smoking in early pregnancy-a population study of women in their first pregnancy in Sweden. J Epidemiol Community Health. 1996;50:33-39.

28. Cnattingius $S$, Haglund B. Decreasing smoking prevalence during pregnancy in Sweden: the effect on small-for-gestational-age births. Am J Public Health. 1997;87:410-3.

29. Hogberg Ulf, Larsson N. Early dating by ultrasound and perinatal outcome: a cohort study. Obstet Gynecol Surv. 1998;53:404-5.

30. Maršál K, Persson P-H, Larsen T, Lilja H, Selbing A, Sultan B. Intrauterine growth curves based on ultrasonically estimated foetal weights. Acta Paediatr. 1996;85:843-8.
31. Persson M, Razaz N, Tedroff K, Joseph KS, Cnattingius S. Five and 10 min Apgar scores and risks of cerebral palsy and epilepsy: population based cohort study in Sweden. BMJ 2018;360:k207.

32. Ludvigsson JF, Andersson E, Ekbom A, Feychting M, Kim J-L, Reuterwall C, et al. External review and validation of the Swedish national inpatient register. BMC Public Health. 2011;11:450.

33. Scheike TH, Martinussen T. On Estimation and Tests of Time-Varying Effects in the Proportional Hazards Model. Scand J Stat. 2004;31:51-62.

34. Perkonigg A, Kessler RC, Storz S, Wittchen HU. Traumatic events and posttraumatic stress disorder in the community: Prevalence, risk factors and comorbidity. Acta Psychiatr Scand. 2000;101:46-59.

35. O'Donnell KJ, Meaney MJ. Fetal origins of mental health: the developmental origins of health and disease hypothesis. Am J Psychiatry. 2017;174:319-28.

36. Milanak ME, Gros DF, Magruder KM, Brawman-Mintzer O, Frueh BC. Prevalence and features of generalized anxiety disorder in Department of Veteran Affairs primary care settings. Psychiatry Res. 2013;209:173-9.

37. Stander VA, Thomsen CJ, Highfill-McRoy RM. Etiology of depression comorbidity in combat-related PTSD: a review of the literature. Clin Psychol Rev. 2014;34:87-98.

38. Frisell T, Öberg S, Kuja-Halkola R, Sjölander A. Sibling comparison designs: bias from non-shared confounders and measurement error. Epidemiology. 2012;23:713-20.

39. Griliches Z. Siblings models and data in Economics: Beginning of a survey. J Polit Econ. 1979;87:S37-S64

40. Layte R, Whelan CT. Explaining social class inequalities in smoking: the role of education, self-efficacy, and deprivation. Eur Socio Rev. 2009:25:399-410.

41. Frissa S, Hatch SL, Gazard B, Fear NT, Hotopf M. Trauma and current symptoms of PTSD in a South East London community. Soc Psychiatry Psychiatr Epidemiol. 2013;48:1199-209.

42. Reidpath DD, Burns C, Garrard J, Mahoney M, Townsend M. An ecological study of the relationship between social and environmental determinants of obesity. Heal Place. 2002;8:141-5.

43. Svensson AC, Pawitan Y, Cnattingius S, Reilly M, Lichtenstein P. Familial aggregation of small-for-gestational-age births: The importance of fetal genetic effects. Am J Obstet Gynecol. 2006;194:475-9.

44. Svensson AC, Sandin S, Cnattingius S, Reilly M, Pawitan Y, Hultman CM, et al. Maternal effects for preterm birth: a genetic epidemiologic study of 630,000 families. Am J Epidemiol. 2009;170:1365-72.

45. Duncan LE, Cooper BN, Shen H. Robust Findings From 25 Years of PSTD Genetics Research. Curr Psychiatry Rep. 2018;20:115.

46. True WR, Rice J, Eisen SA, Heath AC, Goldberg J, Lyons MJ, et al. A Twin Study of Genetic and Environmental Contributions to Liability for Posttraumatic Stress Symptoms. Arch Gen Psychiatry. 1993;50:257-64.

47. Sartor CE, McCutcheon WV, Pommer NE, Nelson EC, Grant JD, Duncan AE, et al. Common genetic and environmental contributions to post-traumatic stress disorder and alcohol dependence in young women. Psychol Med. 2011;41:1497-505

48. Meier SM, Trontti K, Purves KL, Als TD, Grove J, Laine M, et al. Genetic Variants Associated with Anxiety and Stress-Related Disorders: a Genome-Wide Association Study and Mouse-Model Study. JAMA Psychiatry. 2019;76:924-32.

49. Clausson B, Lichtenstein P, Cnattingius S. Genetic influence on birthweight and gestational length determined by studies in offspring of twins. BJOG An. Int J Obstet Gynaecol. 2000;107:375-81.

50. Zhang G, Feenstra B, Bacelis J, Liu X, Muglia LM, Juodakis J, et al. Genetic associations with gestational duration and spontaneous preterm birth. $\mathrm{N}$ Engl J Med. 2017;377:1156-67.

51. Bergh C, Hiyoshi A, Eriksson M, Fall K, Montgomery S. Shared unmeasured characteristics among siblings confound the association of Apgar score with stress resilience in adolescence. Acta Paediatr. 2019:apa.14881.

52. Franchi-Pinto C, Duccini Dal Colletto GM, Krieger H, Beiguelman B. Genetic effect on Apgar score. Genet Mol Biol. 1999;22:13-16.

53. Pakizegi B. Emerging family forms: single mothers by choice-demographic and psychosocial variables. Matern Child Nurs J. 1990;19:1

54. Rindner L, Nordeman L, Strömme G, Svenningsson I, Premberg Å, Hange D, et al. Prognostic factors for future mental, physical and urogenital health and work ability in women, 45-55 years: a six-year prospective longitudinal cohort study. BMC Women's Health. 2020;20:171.

55. Shepherd-Banigan M, Kelley ML, Katon JG, Curry JF, Goldstein KM, Brancu M, et al. Paternal history of mental illness associated with posttraumatic stress disorder among veterans. Psychiatry Res. 2017;256:461-8.

56. D'Onofrio BM, Lahey BB, Turkheimer E, Lichtenstein P. Critical need for familybased, quasi-experimental designs in integrating genetic and social science research. Am J Public Health. 2013;103:S46-55.

57. Hollander AC, Askegård K, Iddon-Escalante C, Holmes EA, Wicks S, Dalman C. Validation study of randomly selected cases of PTSD diagnoses identified in a 
Swedish regional database compared with medical records: Is the validity sufficient for epidemiological research? BMJ Open. 2019;9:e031964.

58. Frisell T, Öberg S, Kuja-Halkola R, Sjölander A. Sibling Comparison Designs: Bias From Non-Shared Confounders and Measurement Error. Epidemiology. 2012;23:713-20.

59. D'Onofrio BM, Lahey BB, Turkheimer E, Lichtenstein P. Critical need for familybased, quasi-experimental designs in integrating genetic and social science research. Am J Public Health. 2013;103:S46-55.

60. Abrevaya J. Trends and determinants of second-pregnancy smoking among young-adult mothers who smoked during their first pregnancy. Nicotine Tob Res. 2008;10:951-7.

61. Flouri E, Francesconi M, Midouhas E, Lewis G. Prenatal and childhood adverse life events, inflammation and depressive symptoms across adolescence. J Affect Disord. 2020;260:577-82.

62. Schuck AM, Widom CS. Posttraumatic stress disorder in maltreated children grown up: the influence of neighborhood. J Trauma Stress. 2019;32:78-87.

\section{ACKNOWLEDGEMENTS}

This study was supported by the China Scholarship Council (to Ms YL), Grant of Excellence, Icelandic Research Fund (grant number: 163362-051, to Dr. UAV), ERC Consolidator Grant (grant number: 726413, to Dr UAV), and Swedish Research Council (grant number: 2016-02234, to Dr UAV and 2020-01003 to Dr DL). We also acknowledge the financial support from the Swedish Research Council through the Swedish Initiative for Research on Microdata in the Social And Medical Sciences (SIMSAM) framework (grant number: 340-2013-5867).

\section{AUTHOR CONTRIBUTIONS}

$\mathrm{YL}$, UAV, and $\mathrm{DL}$ conceived the study. $\mathrm{YL}$ and $\mathrm{DL}$ analyzed data. $\mathrm{YL}, \mathrm{UAV}$, and $\mathrm{DL}$ drafted the paper. AS, HS, SC, FF, QY, LF, DMC, GB, JL, WZ, KF, BMD, CA, and PL contributed to data interpretation and paper writing.

\section{COMPETING INTERESTS}

The authors declare no competing interests.

\section{ADDITIONAL INFORMATION}

Supplementary information The online version contains supplementary materia available at https://doi.org/10.1038/s41380-021-01406-5.

Correspondence and requests for materials should be addressed to Unnur A. Valdimarsdóttir or Donghao Lu.

Reprints and permission information is available at http://www.nature.com/ reprints

Publisher's note Springer Nature remains neutral with regard to jurisdictional claims in published maps and institutional affiliations.

(i) Open Access This article is licensed under a Creative Common Attribution 4.0 International License, which permits use, sharing, adaptation, distribution and reproduction in any medium or format, as long as you give appropriate credit to the original author(s) and the source, provide a link to the Creative Commons license, and indicate if changes were made. The images or other third party material in this article are included in the article's Creative Commons license, unless indicated otherwise in a credit line to the material. If material is not included in the article's Creative Commons license and your intended use is not permitted by statutory regulation or exceeds the permitted use, you will need to obtain permission directly from the copyright holder. To view a copy of this license, visit http://creativecommons. org/licenses/by/4.0/.

(c) The Author(s) 2021 